\title{
New results on equatorial thermospheric winds and temperatures from Ethiopia, Africa
}

\author{
Fasil Tesema $^{1,2,5}$, Rafael Mesquita ${ }^{2}$, John Meriwether ${ }^{2}$ Baylie Damtie $^{1}$, Melessew Nigussie ${ }^{1}$, Jonathan Makela $^{3}$, \\ Daniel Fisher $^{3}$, Brian Harding ${ }^{3}$, Endawoke Yizengaw ${ }^{4}$, and Samuel Sanders ${ }^{2}$ \\ ${ }^{1}$ Washera Geospace and Radar Science Laboratory, Bahir Dar University, Bahir Dar, Ethiopia \\ ${ }^{2}$ Department of Physics and Astronomy, Clemson University, Clemson, South Carolina, USA \\ ${ }^{3}$ Department of Electrical and Computer Engineering, University of Illinois at Urbana-Champaign, Urbana, Illinois, USA \\ ${ }^{4}$ Institute for Scientific Research, Boston College, Boston, Massachusetts, USA \\ ${ }^{5}$ Department of Physics, Wollo University, Dessie, Ethiopia \\ Correspondence to: Fasil Tesema (fasgibe@yahoo.com, fasgibda@gmail.com)
}

Received: 25 August 2016 - Revised: 2 February 2017 - Accepted: 14 February 2017 - Published: 3 March 2017

\begin{abstract}
Measurements of equatorial thermospheric winds, temperatures, and $630 \mathrm{~nm}$ relative intensities were obtained using an imaging Fabry-Perot interferometer (FPI), which was recently deployed at Bahir Dar University in Ethiopia $\left(11.6^{\circ} \mathrm{N}, 37.4^{\circ} \mathrm{E}, 3.7^{\circ} \mathrm{N}\right.$ magnetic). The results obtained in this study cover 6 months ( 53 nights of useable data) between November 2015 and April 2016. The monthly-averaged values, which include local winter and equinox seasons, show the magnitude of the maximum monthly-averaged zonal wind is typically within the range of 70 to $90 \mathrm{~ms}^{-1}$ and is eastward between 19:00 and 21:00 LT. Compared to prior studies of the equatorial thermospheric wind for this local time period, the magnitude is considerably weaker as compared to the maximum zonal wind speed observed in the Peruvian sector but comparable to Brazilian FPI results. During the early evening, the meridional wind speeds are 30 to $50 \mathrm{~ms}^{-1}$ poleward during the winter months and 10 to $25 \mathrm{~ms}^{-1}$ equatorward in the equinox months. The direction of the poleward wind during the winter months is believed to be mainly caused by the existence of the interhemispheric wind flow from the summer to winter hemispheres. An equatorial wind surge is observed later in the evening and is shifted to later local times during the winter months and to earlier local times during the equinox months. Significant night-to-night variations are also observed in the maximum speed of both zonal and meridional winds. The temperature observations show the midnight temperature maximum (MTM) to be generally present between 00:30 and 02:00 LT. The amplitude of the MTM was $\sim 110 \mathrm{~K}$ in January 2016
\end{abstract}

with values smaller than this in the other months. The local time difference between the appearance of the MTM and a pre-midnight equatorial wind was generally 60 to $180 \mathrm{~min}$. A meridional wind reversal was also observed after the appearance of the MTM (after 02:00 LT). Climatological models, HWM14 and MSIS-00, were compared to the observations and the HWM14 model generally predicted the zonal wind observations well with the exception of higher model values by $25 \mathrm{~ms}^{-1}$ in the winter months. The HWM14 model meridional wind showed generally good agreement with the observations. Finally, the MSIS-00 model overestimated the temperature by 50 to $75 \mathrm{~K}$ during the early evening hours of local winter months. Otherwise, the agreement was generally good, although, in line with prior studies, the model failed to reproduce the MTM peak for any of the 6 months compared with the FPI data.

Keywords. Atmospheric composition and structure (airglow and aurora) - ionosphere (equatorial ionosphere) - meteorology and atmospheric dynamics (thermospheric dynamics)

\section{Introduction}

Temporal and spatial variations in thermospheric neutral atmosphere parameters, such as density, velocity and temperature, drive a complex system of ionospheric currents and electric fields which are necessary to accurately describe equatorial thermosphere-ionosphere dynamics. Globally, the 
thermospheric neutral wind circulation is driven by multiple forces including the solar-heating pressure gradient, ion drag, convection (high latitudes), viscous drag, and the Coriolis force. The equatorial zonal neutral wind dominates the F-region plasma circulation by providing momentum transfer through ion-neutral collisions. This F-region coupling is manifested by significant nighttime fluctuations of the observed neutral winds and temperatures and has a strong impact on the evolution of plasma irregularities through the control of the dynamo electric field (Rishbeth, 1971; Heelis, 2004; Huba and Krall, 2013). During daytime, the dynamo currents produced by thermospheric winds in the $\mathrm{F}$ region are short-circuited by the conducting E region. However, after sunset, the increase in eastward wind component in combination with the sharp day to night $\mathrm{E}$ region conductivity gradient across the terminator leads to the enhancement in the eastward electric field. This enhanced field produces further upward $\boldsymbol{E} \times \boldsymbol{B}$ drift and lifts the F region over the geomagnetic equator to high altitudes, where recombination is slow. The evolution of the early evening ionospheric dynamics causes the bottomside F-region plasma density gradient to become unstable and cause the formation of a complex equatorial plasma structure commonly referred to as equatorial spread F (Kelley, 2009). This instability - which commonly manifests itself in a variety of ways, including a spread in the F-region echoes of an ionogram, intensity depletions in thermosphere airglow, plumes in VHF radar echoes, and total electron content (TEC) depletions in GPS measurements - will affect radio signals propagating through the disturbed region, causing scintillation and subsequent disruptions in communication and navigation systems (Mendillo et al., 1997; Pimenta et al., 2007; Haase et al., 2011).

Satellite observations show evidence for unique equatorial ionospheric structures that appear only in the African sector, where bubbles have a much larger depth and occur more frequently as compared to other longitudinal sectors (Hei et al., 2005; Su, 2005; Gentile et al., 2011; Yizengaw et al., 2011). It was also reported that the ionospheric depletions in this region rise to high altitudes more frequently compared to other longitudes (Burke et al., 2004). However, these observations have not been validated or studied in detail by measurements on the ground due to a lack of suitable ground-based instrumentation in the region. Thus, the development and evolution of these unique plasma density irregularities in the African longitudinal sector remain to be fully understood.

Several studies using satellite and ground-based instrumentation have shown the dynamics of the African region. For example, (Yizengaw et al., 2014) reported that the magnitude of the pre-reversal enhancement (PRE) vertical drift, which is associated with the enhancement of evening $\boldsymbol{E} \times \boldsymbol{B}$ drift, is very small as compared to what has been seen in the American sector. This study also reported that TEC depletions (indications of spread F) are observed more frequently in this sector than the American sector, which contradicts the understanding of the direct relationship between the mag- nitude of the vertical drift and the ensuing development of strong plasma irregularities. The question of how plasma irregularities become strong and persistent in the African sector in spite of the weak magnitude of PRE is unanswered. It was suggested that knowledge of neutral dynamics is crucial to fully understand the cause of this unique characteristics of F-region plasma irregularities in the African sector. However, until now, no appreciable observing effort had been made to study the dynamics of neutral thermosphere winds in the African sector.

The other focus found in previous published work regarding the equatorial coupled thermosphere-ionosphere system is centered upon the nocturnal variation in equatorial and low latitude neutral temperatures. The large-scale neutral temperature peak, seen near midnight and thus called the midnight temperature maximum (MTM), has been shown to result from the convergence of equatorward meridional winds from southern and northern hemispheres interacting with tidal oscillations propagating into the thermosphere from the lower atmosphere. The MTM peak region starts near the geographic equator and propagates poleward and westward in both hemispheres reaching the midlatitudes (Colerico and Mendillo, 2002; Colerico et al., 2006). The MTM magnitude has been reported to range from 20 to $540 \mathrm{~K}$ in South America, North America, Arecibo and the Indian longitudinal sector (Spencer et al., 1979; Sastri and Rao, 1994; Colerico and Mendillo, 2002; Colerico et al., 2006; Meriwether et al., 2008; Martinis et al., 2013; Hickey et al., 2014). This temperature enhancement is related to an accompanying reversal of the meridional winds that affects the vertical distribution of the plasma in the off-equator regions and leads to interesting optical phenomena, such as the midnight collapse and brightness wave (Wiens et al., 2004; Colerico et al., 2006).

The impact of the thermospheric neutral wind to the development of the ionospheric dynamics in the African sector near the geomagnetic equator has received little attention partly due to a lack of ground-based Fabry-Perot interferometer (FPI) observations of thermospheric winds. Quite a few similar studies have been carried out using either observations collected over a small period of time or observations made at midlatitudes (Vila et al., 1998; Wiens et al., 2004; Fisher et al., 2015). Thus, the FPI instrument that has recently been installed at Bahir Dar University, Ethiopia, will provide valuable data that will help us to have a more complete understanding of the global picture of equatorial thermospheric dynamics. In this paper, the first results of FPI-measured monthly-averaged equatorial vector winds and temperature obtained over a period of 6 months in the African longitudinal sector shows several differences relative to similar results obtained in other longitude sectors. 


\section{Instrument and data analysis}

The FPI instrument used for this study is an optical instrument that measures in high resolution the spectral line shape of the airglow emission originating in the spectral transition for a specific wavelength. The particular wavelength used in this study is the $630 \mathrm{~nm}$ red line emission coming from the $630 \mathrm{~nm}$ airglow layer extending from 225 to $275 \mathrm{~km}$ produced as a result of the dissociative recombination of $\mathrm{O}_{2}^{+}$ (Wickwar et al., 1974). Estimates of thermospheric line-ofsight wind speed and temperature may be obtained from the measured Doppler shift and Doppler broadening of this redline emission, respectively. The $630 \mathrm{~nm}$ emission relative intensity is proportional to the spectral area of this spectral lineshape. The FPI system uses an etalon with an air gap of $1.5 \mathrm{~cm}, 70 \mathrm{~mm}$ clear aperture, and interior etalon surfaces coated with a reflectivity of $\sim 77 \%$. A $0.7 \mathrm{~nm}$ narrowband filter centered at $630.0 \mathrm{~nm}$ with $\sim 55 \%$ transmission is placed in the optical path before the etalon to isolate the redline emission. An objective lens focuses the interference image onto the front face of a low-noise square CCD chip (Andor iKon-M 934 camera with low readout $(2.5 e-$ ) and dark noise $0.001 e-/ \mathrm{pixel} / \mathrm{s} @-90^{\circ} \mathrm{C}$ ) with an imaging area of $13.3 \times 13.3 \mathrm{~mm}$ in dimension (see Shiokawa et al., 2012, for more details).

A SkyScanner system designed with motors to drive two coupled reflecting mirrors is placed above the FPI optics to observe the sky in any direction by rotating in the elevation (el) and the azimuth (az) planes. For a single FPI deployment, the typical observing scenario would observe the calibration laser, the vertical (zenith) direction, followed by each of the four cardinal directions, namely east, west, north and south at a zenith angle of $45^{\circ}$. Figure 1 shows the location of the FPI deployed at Bahir Dar University in Ethiopia, Africa $\left(11.6^{\circ} \mathrm{N}, 37.4^{\circ} \mathrm{E}, 3.7^{\circ} \mathrm{N}\right.$ magnetic), and all viewing directions of the FPI for an airglow layer altitude of $250 \mathrm{~km}$. With an integration time of $300 \mathrm{~s}$ for the $630 \mathrm{~nm}$ sky emissions, and $30 \mathrm{~s}$ for the laser calibration and accounting for system overhead (to read out the CCD detector and move the SkyScanner), a typical observing cycle takes $\sim 27 \mathrm{~min}$. Laser measurements are implemented by observing a frequency stabilized $\mathrm{HeNe}$ laser that provides the calibration of the FPI instrument function that is required for the determination of temperatures and Doppler's zero-wind reference (Meriwether et al., 2011; Shiokawa et al., 2012). Uniformity in the laser source is produced by using a scattering chamber. The resulting source is bright enough to pass through the stop bands of the filter used to create a ring pattern, which can be considered as an impulse response of the system (Shiokawa et al., 2012).

Data are analyzed based on the method described in (Harding et al., 2014). Briefly, analysis of the laser interference pattern determines the effective parameters of the FPI instrument function such as the etalon gap, reflectivity, and optical defects. This can be done by fitting the laser fringes with a

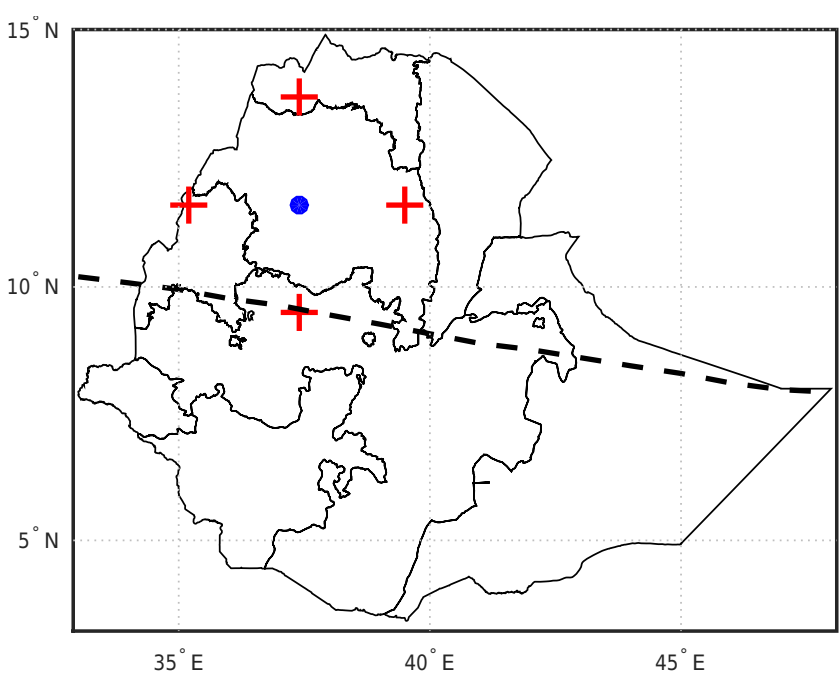

Figure 1. Map of Ethiopia showing the location of the FPI observatory and the zenith look direction (blue dot). The four cardinal FPI look directions are north, south, east and west as indicated by the red crosses. Also plotted (dashed black line) is the geomagnetic equator.

modified Airy function, which contains a blurring function that takes into account the optical defects. As the full width at half maximum width of the laser emission is much smaller than that of the sky emission of interest, the laser function serves as a delta function from which the best values of these instrumental parameters can be obtained.

Once the FPI instrument function has been obtained, the sky emission interferograms can be analyzed. The interference ring pattern for each sky image is first annularly integrated into a 1-D interferogram that is then analyzed to obtain the four data products of Doppler peak position, Doppler broadening, spectral area, and the background (Makela et al., 2011). A Levenberg-Marquardt nonlinear least-squares fitting algorithm is used to find the optimal estimates and standard deviations of a four-parameter model for each interferogram. The unknown zero-wind reference is determined by assuming that the average vertical wind over the night is zero, and then the line-of-sight measurements are transformed to get the horizontal zonal and meridional wind components (Makela et al., 2011; Shiokawa et al., 2012). This analysis also determines the spectral area of the lineshape, which is proportional to the $630 \mathrm{~nm}$ volume emission rate integrated along the line of sight from the observatory.

The cloud sensor installed at the Bahir Dar site location is used to report the observing conditions. This sensor covers a field of view of $80^{\circ}$ and measures the infrared radiation from the sky to determine the sky temperature and this will be compared to the ambient ground temperature to deduce the cloud coverage (Makela et al., 2012). Clear skies are characterized by values of $-20^{\circ} \mathrm{C}$ and lower, and cloudy skies by values of $-10^{\circ} \mathrm{C}$ and higher (Fisher et al., 2015). These 
Table 1. Number of nights averaged in each month and the corresponding averaged solar flux and geomagnetic indices.

\begin{tabular}{lrrr}
\hline Month & Nights & Respective daily average Kp & Averaged F10.7 \\
\hline November & $01,02,06,08,09,11,12,13,14$ & $2.1,0.9,2.7,2.4,3.8,3.5,1,2.5,2$ & 107.7 \\
December & $05,07,08,11,12,13,14,15$ & $2.8,3.4,2.3,3.3,2.3,1.6,2.9,2.8$ & 107.7 \\
January & $03,04,05,06,07,08,09,10,11,12,13$ & $1.6,1.1,1.4,3,2.7,1.8,1.4,2,2.6,2.7,2.5$ & 100 \\
February & $02,03,04,05,06,07,08,09,11$ & $2.2,1.9,1.2,2.4,1.7,1.8,2.4,1.9,2$ & 11.4 \\
March & $01,03,04,05,06,08,09,10,11,12$ & $2,1.6,0.8,0.7,3.1,1.8,1.6,1.8,3.1,2.3$ & 94.8 \\
April & $03,04,05,08,09,10$ & $2.6,1.4,1.3,1.3,0.3,1.5$ & 94.2 \\
\hline
\end{tabular}

results are used to determine the FPI data quality in which FPI data associated with cloud temperature values above the cutoff value of $-10^{\circ} \mathrm{C}$ are excluded from the analysis. The monthly-averaging analysis is implemented after filtering the data to discard the low-quality data. Thus, values are not considered if the uncertainties of wind and temperature are equal to or greater than $25 \mathrm{~ms}^{-1}$ and $50 \mathrm{~K}$, respectively. Estimations of winds and temperatures are ignored for periods of weak airglow intensities because of contamination by $\mathrm{OH}$ emission lines, causing large errors in wind and temperature estimates (Hernandez et al., 1974; Burnside et al., 1977). The remaining FPI measurements after filtering are sorted into a $30 \mathrm{~min}$ bin for the wind measurements and $20 \mathrm{~min}$ for the temperature measurements for each month of observation. For each bin, a statistical analysis is done by computing the weighted mean and standard deviation. The vertical bars plotted in the monthly-averaged figures represent the variability in the wind and temperature values within the given averaging bin. The HWM14 and MSIS-00 model predictions are computed for an average bin width of $30 \mathrm{~min}$ for the winds and temperatures of selected nights.

\section{Results}

The FPI system at Bahir Dar University, Ethiopia, was deployed in the month of May 2015. Right after the deployment the continual cloudy skies caused by the Intertropical Convergence Zone (ITCZ) started and continued to August. Unfortunately, several technical problems prevented operations in September and October. Therefore, this study used the data for nights of November 2015 to April 2016, a total of 53 nights. Table 1 lists the number of nights for each month and the corresponding averaged solar flux (F10.7) and geomagnetic activity values. Generally, the solar activity remained nearly constant ranging between 94 and 111 flux units, and the geomagnetic activity was quiet for all nights.

Figure 2 illustrates the variability in the zonal and meridional winds, temperature and intensity during successive nights between 4 and 9 February 2016. The magnitude of the zonal wind varies between 0 and $100 \mathrm{~ms}^{-1}$ during these nights. A significant variation in the night-to-night winds is seen during the predawn period, showing a rapid decrease in magnitude toward zero. However, for several nights (for ex- ample, 8 and 9 February) higher values of zonal wind (above $50 \mathrm{~ms}^{-1}$ ) occurred just before dawn. The meridional wind speed showed considerable variation during these nights before becoming equatorwards in direction. A poleward wind is evident before the equatorward wind surge, which began to take effect at a different time on each night. After midnight a reduction in the equatorward wind toward zero is observed in all these nights, with a reversal toward the poleward direction observed for the nights of 6, 7, and 9 February.

The temperature observations show significant night-tonight variations for the nights considered in Fig. 2. This variation is most notable between early evening and midnight hours. During this time, the temperature values from different viewing directions are not the same, which are seen as scattered points (third row of Fig. 2) except on 8 February. The MTM signature, whose magnitude is inferred based on a straight line fitting described in (Meriwether et al., 2008), is clearly seen during these days, which appears just before the abatement/reversal of the meridional wind and after several hours of the equatorward meridional wind. The magnitude of the MTM varies between 40 and $140 \mathrm{~K}$. It can be observed that there are a few data points that show temperature values below $700 \mathrm{~K}$. These low values and the scattered values of the temperature from all viewing directions are seen when the signal intensity of $630 \mathrm{~nm}$ emission is very weak. This consistency can be seen by comparing panels in the lower two rows of Fig. 2. Typical very low signal intensity values were observed between 19:30 and 23:00 LT and between 04:30 and 05:30 LT. The intensities in different look directions are generally the same, except for those in the northern viewing direction (green dots) that show higher values of $630 \mathrm{~nm}$ signal intensity when compared to the other look directions. Moreover, an offset of $1 \mathrm{~h}$ is typically seen between the times of the MTM peak and the $630 \mathrm{~nm}$ intensity peak.

Figure 3 presents the monthly-averaged values of the winds from November 2015 to April 2016. Observations typically begin just after twilight at nearly 19:00 LT. For the months between November and April, the beginning of data collection shifts to later local time and ends at an earlier local time. The left-hand side panels of Fig. 3 show the zonal wind from November 2015 to April 2016. The magnitude of zonal wind during the early evening hours is between 50 and $100 \mathrm{~ms}^{-1}$ with the highest and lowest values observed 


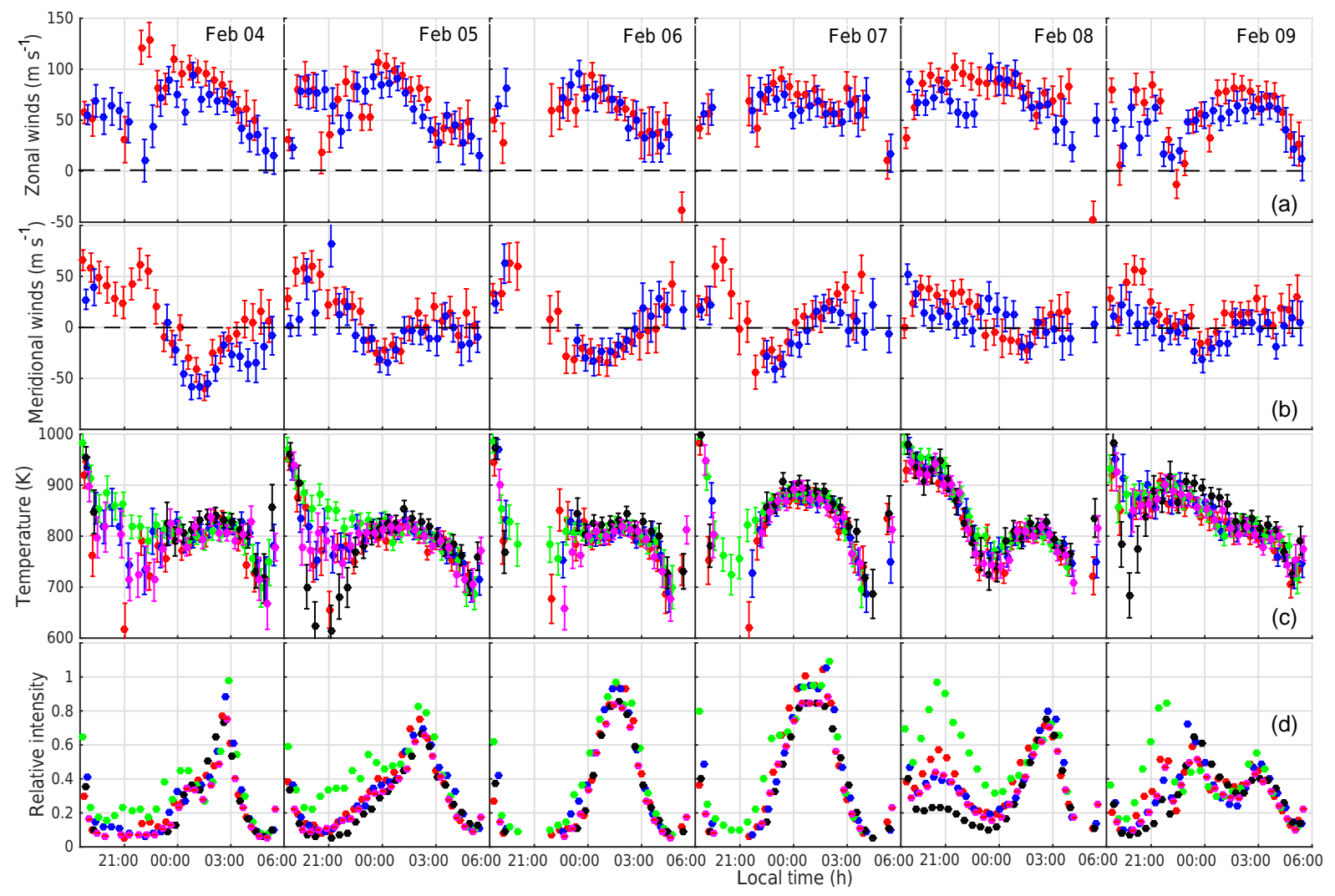

Figure 2. Sequential nights (4 to 9 February 2016) of zonal wind measurements (top row) for west (red dots) and east (blue dots) directions, meridional wind measurements (second row) for south (red dots) and north (blue dots) directions, and temperature (third row) and relative intensity (bottom row) from all viewing directions (east, west, north, south and zenith, in red, blue, green, black and magenta, respectively).

in April and November, respectively. Significant differences in the magnitude and characteristics of the zonal winds have been observed after local midnight during the entire observation period. The zonal winds in November and March months continue into the night with speeds that remain nearly constant. However, the zonal winds for other months show a gradual decrease with a maximum decrease in the April month. This gradual decrease continues until the end of the night where the values reach $\sim 10 \mathrm{~ms}^{-1}$.

A monthly-averaged plot of meridional wind speeds observed during this study is presented in the right-hand side of Fig. 3. Meridional wind speeds in the early evening hours varied depending upon the season. In winter months (November, December and January) the poleward wind values reach $100 \mathrm{~ms}^{-1}$, followed by a decrease and a shift to the equatorward direction and later local times during the months of November to January. During the equinox months (February, March, and April), the magnitude of the poleward wind at the beginning of the night was observed to be weak. The period of equatorward wind flow started at a later time in February and became evident at an earlier time in March and April. The equatorial wind speeds after local midnight show abatement and/or reversal from equatorward to poleward. The strong poleward wind after midnight was observed during the winter months, in which the magnitude of the equatorward wind surge was very small, lasting for a short period. During the equinox months, the equatorward wind was observed near the beginning of the night and remained equatorward in direction for about $3 \mathrm{~h}$, with a maximum value of $80 \mathrm{~ms}^{-1}$ in April.

The temperature plots shown in Fig. 4 clearly show a month-to-month variation. The MTM peak value and the time of occurrence differ from month to month. The MTM peak amplitude is high in January with a value of $110 \mathrm{~K}$ at about 00:30 LT, but in November, March, and April the MTM peak is seen after 01:30 LT and in December at nearly local midnight. However, during December and February MTM shows an extended and weak magnitude. The decrease in temperature values at the beginning of the night is seen in all months with a gradual decrease until the signature of the MTM peak began to appear after 22:30 LT.

The comparisons of wind and temperature monthlyaveraged values with empirical model results are shown in Figs. 3 and 4, respectively. The predictions from the HWM14 model are used to compare with the wind speeds measured as shown in Fig. 3. In general, the model predicts the ob- 

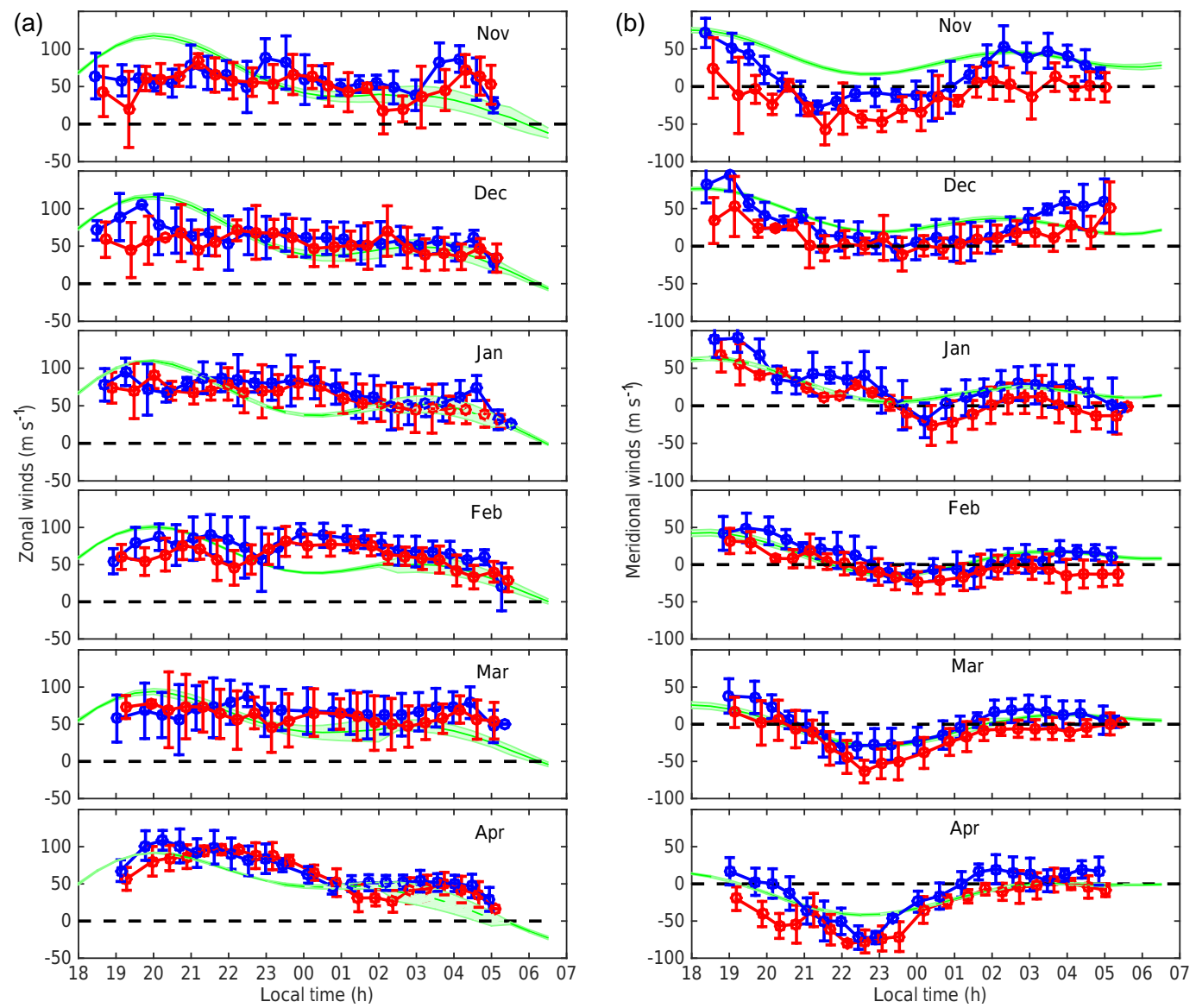

Figure 3. Monthly-averaged winds between November 2015 and April 2016 for a time bin of 30 min. The left panel shows the zonal wind data for east (blue) and west (red) directions. The right panel shows the meridional wind data for north (blue) and south (red) directions. Also shown are the HWM14 model results (green) for the zonal and meridional speed variations averaged for the nights included in each month. The thickness for each model curve indicates the range of variability. The vertical bar shows the overall range of variation within each averaging bin.

servations very well, with a few exceptions. In the zonal wind comparison, between 23:30 and 01:30 LT, the HWM14 model and the observations show a noticeable discrepancy in January and February. For November and December the disagreement is seen during the early evening hours (19:30 to 21:30 LT). However, the meridional wind showed very good agreement from January to April 2016. For November and December, the comparison of the data with the HWM model shows a discrepancy of 30 to $50 \mathrm{~ms}^{-1}$, most noticeable before midnight and similarly, for the predawn sector.

Comparisons of the MSIS-00 model results with the data are depicted in Fig. 4. In the early evening period, the model overestimates the temperature values in the winter months (November, December and January). The temperature data and the model results show very good agreement for the February and March months. In all the months considered in this study, the MSIS-00 model fails to reproduce the observed magnitude of MTM peaks as seen in the FPI temperature plots.
Figure 5 shows the monthly-averaged values of $630 \mathrm{~nm}$ emission intensity and vertical wind observed in this study. The horizontal dotted line on the intensity plots is the minimum intensity needed to be used for the reliable determination of temperature and winds. This minimum intensity value (quality threshold) is determined by correlating all the zenith measurements made with the intensity values to find the intensity which shows a small downward vertical wind. The large downward vertical wind could be due to the possible contamination of the signal originating from the $\mathrm{OH}$ emission layer at $85 \mathrm{~km}$ (Hernandez et al., 1974; Burnside et al., 1977). In general, the intensity curves show the same characteristics, starting with high values, decreasing to smaller values quickly, and then returning to become high after 23:30 LT, and reach a maximum value at 03:00 LT before finally decreasing to smaller values.

The vertical winds shown in the right panels of Fig. 5 illustrate a significant month-to-month variation. A significant downward vertical wind is observed in the early 

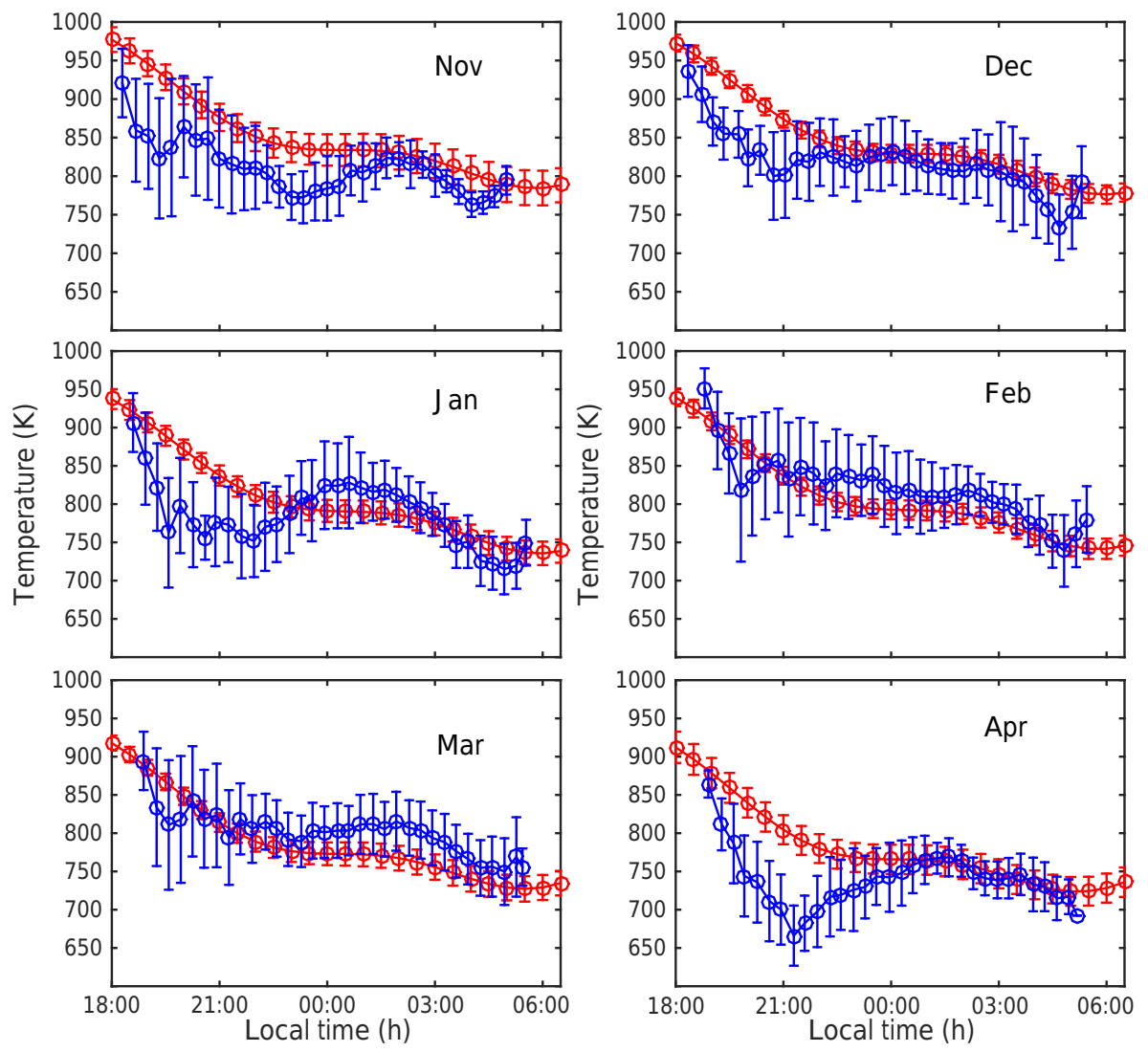

Figure 4. Monthly-averaged temperature observations (blue curves) and MSIS-00 model results (red curves) for an averaging bin period of $20 \mathrm{~min}$. The vertical bar for each bin shows the variation in the data within the averaging bin.

evening hours of January, March, and April months. However, November, December and February show nearly zero values of vertical wind during this period. After 23:30 LT, which is the time when the $630 \mathrm{~nm}$ intensity values became larger, the vertical winds are all nearly zero. At the end of the night, the direction of the vertical wind is downward for December, January, and February. However, as noted above, during times of low signal intensity, the wind observations may be contaminated by the $\mathrm{OH}$ emission (Hernandez et al., 1974; Burnside et al., 1977), and so these vertical wind estimates should be viewed with healthy skepticism.

\section{Discussion}

The results obtained from an imaging FPI deployed at Bahir Dar University in eastern Africa over 6 months of observations (November 2015 to April 2016) show several interesting features. These results are of great importance because they are representative of the thermospheric dynamics near the African geomagnetic equatorial region, where no previous observations have been made. These preliminary results show some similarities but also several differences as com- pared with similar observations obtained in other longitude sectors.

The neutral wind speed, which is observed in the eastern African sector for the first time, appears to be weaker compared with speeds observed in other longitude sectors. The maximum magnitude of the zonal winds in the Peruvian sector may reach $150 \mathrm{~ms}^{-1}$ (Martinis et al., 2001; Meriwether et al., 2011, 2012). However, the magnitude of the zonal wind in the African sector is generally below $100 \mathrm{~ms}^{-1}$, which is also approximately typical of the Brazilian sector (Meriwether et al., 2012; Makela et al., 2013). The reason could be the weak pre-reversal enhancement, which is small in the African sector as compared to the other longitude sectors (Yizengaw et al., 2014). Such weak PRE amplitudes mean that the post-twilight vertical motion may not lift the plasma to high altitudes. Consequently, the ion drag influence upon the eastward flow will have some retarding effect on the eastward speed of thermospheric winds.

Alternatively, reduced ion drag over the Peruvian sector resulting from the uplift of the F-region plasma by a strong PRE may be the major cause of the zonal wind enhancement in Peru. This question will be examined more closely in future work with a modeling calculation of the ion drag reduction that might be expected for the African sector. During 

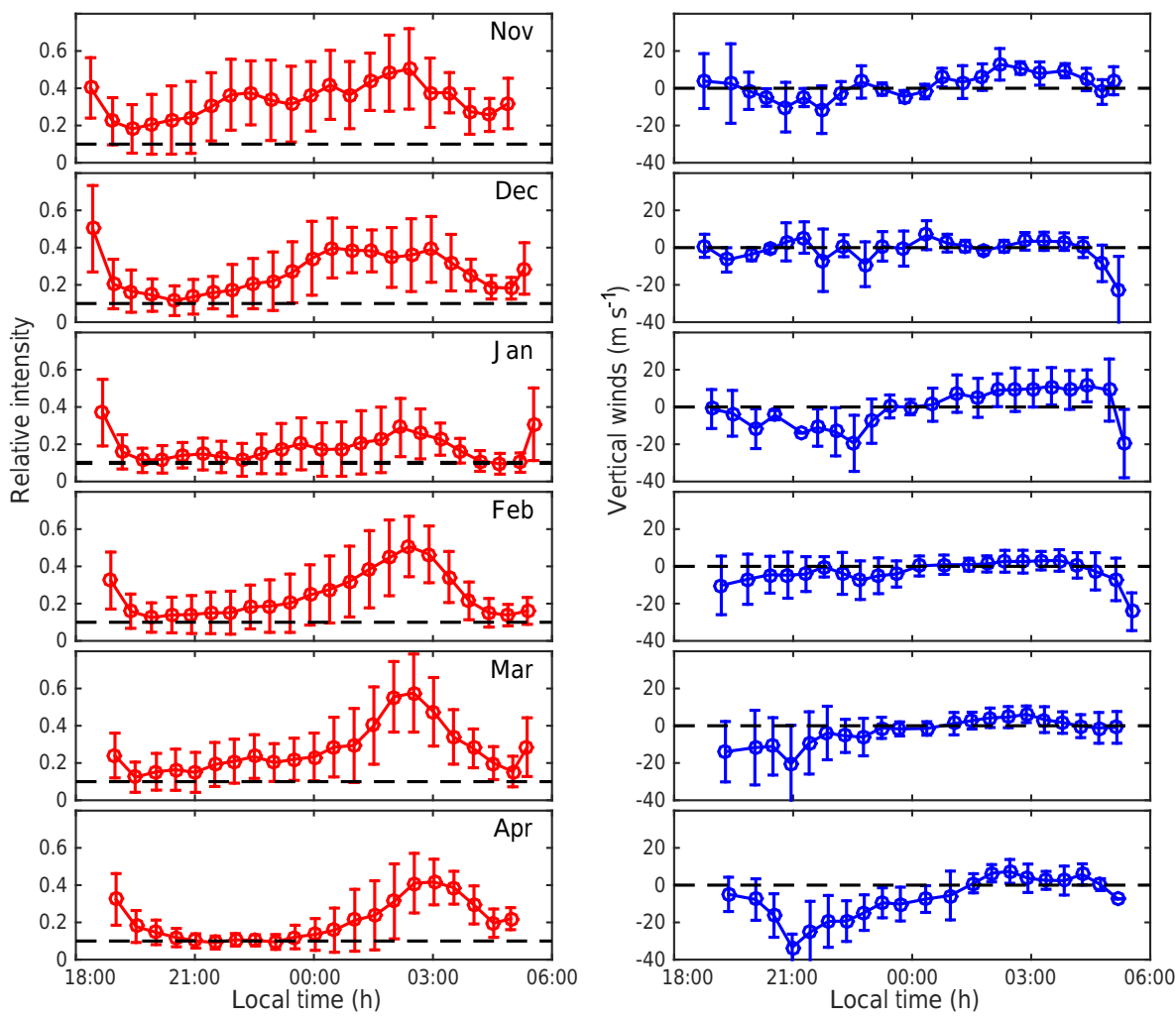

Figure 5. The relative intensity (red curves) and vertical winds (blue curves) averaged for a time bin of 30 min using data for all viewing directions. The vertical bars show the overall range of variation within each averaging bin.

the post-sunset period the ionospheric plasma moves upward to higher altitudes due to the PRE, where the F-region dynamo become effective. This upward motion of the plasma creates a favorable condition for plasma irregularity development in support of the seeding mechanism believed to be the gravity wave propagating from below (Abdu et al., 2009; Taori et al., 2011). Many studies have addressed the characteristics of the plasma irregularity at different seasons, geophysical conditions and longitude sectors. One of the candidates which controls the day-to-day variability in the plasma irregularity is the zonal wind in the sunset period (Basu et al., 1996). The identification of the night-to-night variability seen in Fig. 2 may support the idea of the night-to-night variability in spread-F occurrence, but further measurements are needed for these studies that should be correlated with data from other measurement techniques such as magnetometers and TEC monitors.

The right-hand side of Fig. 3 shows the monthly-averaged meridional winds for the months from November 2015 to April 2016. During the early evening hours of winter months (November, December, and January) there is a strong poleward wind flow with maximum magnitude reaching about $100 \mathrm{~ms}^{-1}$. This strong poleward wind is attributed to interhemispheric flow from the summer to winter hemisphere, and the equatorward wind surge occurrence time shifts to later time from November to January. However, the time shift of the equatorward flow is reversed during the transition from winter to equinox seasons. The values of the wind, temperature or intensity are missing in some of the days during the post-sunset hours and the predawn sectors. This is due to the fact that the plasma density was insufficient (raised to higher altitudes) to produce bright enough $630 \mathrm{~nm}$ airglow for the accurate determination of these parameters.

The temperature observations in Fig. 4 shows a significant month-to-month variation. The MTM signature also varies from month to month, with respect to the time of occurrence and magnitude. The strongest MTM was observed in January, and there are months with weak MTM signatures. The development of the MTM peak is preceded by the equatorward wind flow, which generally reaches a maximum amplitude between 21:30 and 00:30 LT. The amplitude of MTM peak ranges from 50 to $110 \mathrm{~K}$. However, there was an extended weak MTM amplitude in December and February; this is due to the variation in the timing of MTM peak from night to night (see Fig. 2). The strong equinoctial meridional winds (between 50 and $90 \mathrm{~ms}^{-1}$ ) was seen in our results (right panel of Fig. 3). (Meriwether et al., 2008) reported that such a seasonal and strong equatorward wind could be due to the $(2,2)$ tidal mode reinforced by the asymmetric $(2,3)$ tidal wave, which is weak in the winter but strongest dur- 
ing equinoxes. The other possible contributions for this large equatorward wind are from the non-migrating tidal waves. As reported by (Meriwether et al., 2008) and (Colerico et al., 2006) from observations and model results, the terdiurnal tidal wave is also comparable with that of the effect of the semidiurnal tide. This terdiurnal tide can originate from the ion-neutral coupling in the thermosphere due to the nonlinear interactions between the diurnal and semidiurnal tides. The correlations between the weak or non-existence of MTM peak and the absence or weak meridional wind surge suggest that the tidal propagation from lower altitudes and/or the in situ tides are weak. Previous researches reported that the time lag between the wind surge and the appearance of MTM is longer in winter and shorter in equinox season, but our results show that the longer time exists in the equinox season and the shorter time in the winter season (Meriwether et al., 2008, and references therein). Most studies have reported the seasonal variation in the occurrence time of MTM with an earlier time in the summer, nearly midnight in the equinox and after midnight in the winter seasons (Meriwether et al., 2011). However, in this study a strong seasonal variation in the appearance of the MTM peak was not detected. Generally, the time of the MTM signature for all observations was found to be after midnight between the times of 00:30 and 02:00 LT.

The left panel of Fig. 5 shows the monthly-averaged relative intensity for the 6 months from November to April. The general characteristics seen in this figure is a decrease in relative intensities in the post-sunset hours followed by an enhancement by a factor of five or greater for the period just after midnight. This behavior of the intensity is more pronounced in the equinox months. Previous research has reported such enhancements in relative intensity at equatorial, low- and midlatitude regions (Otsuka et al., 2003). In the low- and midlatitude regions, this enhancement is due to the reversal of the meridional wind by the MTM that leads to the descent of the F-layer region plasma to lower altitudes (Wiens et al., 2004). However, in the equatorial latitudes such a rising and falling motion of the F-region plasma is largely controlled by the $\boldsymbol{E} \times \boldsymbol{B}$ electrodynamic drift. This drift is generally upward during the daytime and downward during the nighttime. There is also an enhanced upward drift in the post-sunset hours due to the PRE, when the F-region dynamo is active and contributes to the uplifting of the plasma further before the downward drift of the plasma becomes dominant. The combination of the PRE forcing the plasma layer to rise to high altitudes and the dependence of the $630 \mathrm{~nm}$ production upon the plasma density causes the $630 \mathrm{~nm}$ intensity to decrease significantly. This reduction in the intensity depends on the strength of the PRE, which is reported to be stronger in the equinox seasons than the solstice seasons in this sector (Yizengaw et al., 2014). This may explain the more pronounced weak $630 \mathrm{~nm}$ relative intensity that was observed in February, March and April. The increase in intensity after 23:30 LT is due to the nighttime downward $\boldsymbol{E} \times \boldsymbol{B}$ drift (Bit- tencourt and Sahai, 1979; Colerico et al., 1996). However, a significant day-to-day variability in the intensity is also observed, as shown in Fig. 2. The high $630 \mathrm{~nm}$ intensity seen in the northern viewing direction (green dots) may be attributed to the observing direction $13^{\circ} \mathrm{N}$ toward the equatorial ionization anomaly, which increases $630 \mathrm{~nm}$ intensity generated by the higher EIA plasma density.

The right panel of Fig. 5 shows plots of the monthlyaveraged values of the vertical winds. The possible existence of vertical winds has been reported before (Fisher et al., 2015), but these results still remain to be validated. One concern centers upon the possible introduction of a false Doppler shift into the apparent $630 \mathrm{~nm}$ Doppler line-center position by contamination of the $630 \mathrm{~nm}$ spectral emission profile by weak $\mathrm{OH}$ rotational line emissions that are located near the $630 \mathrm{~nm}$ wavelength (Hernandez et al., 1974; Burnside et al., 1977). Another concern is a possible false Doppler shift caused by light scattering from the bright western horizon (Abreu et al., 1983). This matter will be followed up in a separate investigation (B. J. Harding, J. Qin, and J. J. Makela, personal communication, 2016).

The HWM14 model (Drob et al., 2015) predictions for the zonal and meridional wind speeds agreed well with the Bahir Dar measurements except for two months: November 2015 and February 2016. The model performed well in predicting the meridional wind speeds. The model predictions of zonal wind speeds for the early evening show some small discrepancies for all months presented in this study.

\section{Conclusions}

In summary, the first results on the nighttime monthlyaveraged equatorial thermospheric winds and temperatures for the equatorial East African longitude sector near the geomagnetic equator illustrate many similarities and differences with similar climatologies observed in the Brazilian and Peruvian sectors. The main results are summarized as follows:

1. Significant night-to-night variation in the zonal and meridional winds, temperatures, and relative intensities was observed, illustrating how the balance between the driving factors contributing to the equatorial thermospheric dynamics varies from night to night, i.e., day-today variation in both the magnitudes of the day-to-night pressure gradient and the ion drag associated with the F-region plasma density.

2. The maximum eastward zonal wind speeds are generally weaker (with typical values below $90 \mathrm{~ms}^{-1}$ ) as compared to results from the Peruvian longitude sector.

3. Significant MTM signatures for all nights were observed in this sector with the largest peak values being observed in January $(110 \mathrm{~K})$ and the weakest magnitude of the MTM in February (30 K). 
4. The meridional winds during the early evening show a strong poleward wind in the winter seasons that is attributed to the interhemispheric flow but may also in part be attributed to non-migrating tidal wave forcing. It is notable that there is an equatorward wind surge that shifts in phase to later local times in winter months and to earlier local times in the equinox months. This result is similar to that seen for Peru and Brazil, with all three FPI data sets indicating equatorward tidal winds near 23:00 LT. This indicates a region of meridional wind convergence exists near the geographic equator. There is a positive correlation between the existence of the equatorward wind surge near 23:00 LT and the magnitude of the MTM seen at 00:00 LT.

5. Application of the HWM14 and MSIS-00 climatological models generally found good agreement with the observations over Ethiopia, with some exceptions for winter nights in this study.

6. The $630 \mathrm{~nm}$ relative intensity shows a significant decrease in magnitude in the early evening hours, followed by a strong increase (5-fold) to reach maximum values in the post-midnight period. Such behavior of the $630 \mathrm{~nm}$ intensity was more pronounced for equinoctial nights.

This study presented, for the months from November 2015 to April 2016, monthly-averaged thermospheric winds and temperatures in a sector for which such results have not been previously reported. Further research on the questions involving thermospheric ion-neutral coupling would now be feasible by comparing and coordinating the FPI measurements with other sensor measurements, such as coherent radar, all sky imager, and GNSS receivers. Accordingly, an airglow imager will be installed at the Bahir Dar FPI observatory, which is already collocated with a VHF radar and a SCINDA GPS receiver sensor. These measurements would enable further research on answering outstanding questions regarding the production and evolution of the ionospheric plasma irregularities observed in the African sector.

Data availability. The daily analyzed data plot is displayed on the website http://airglow.ece.illinois.edu/Data/Calendar. For further use of the wind, temperature and intensity data please contact John W. Meriwether (john.meriwether@ces.clemson.edu). For the HWM14 and MSIS-00 model results this paper uses pyglow (Python package for upper atmospheric climatological models), which is freely available at https://github.com/timduly4/pyglow/ (pyglow, 2017).

Competing interests. The authors declare that they have no conflict of interest.
Acknowledgements. The deployment of the FPI system was supported by AFOSR DURIP and travel by the National Science Foundation grant AGS-1452291 to Clemson University. The first author is indebted to Washera Geospace and Radar Science Laboratory (WaGRL), Bahir Dar University and Wollo University for their financial support. The first, fourth and fifth authors' work was supported by the Air Force Office of Scientific Research, Air Force Material Command USAF, under award number FA9550-16-1-0070. In addition the first author would like to thank Clemson University for the aid he received as a visiting scholar. Funding for the University of Illinois group participation was provided by the National Science Foundation grant AGS-1452291.

The topical editor, D. Pallamraju, thanks D. A. Hickey, R. Niciejewski, and one anonymous referee for help in evaluating this paper.

\section{References}

Abdu, M. A., Alam Kherani, E., Batista, I. S., de Paula, E. R., Fritts, D. C., and Sobral, J. H. A.: Gravity wave initiation of equatorial spread F/plasma bubble irregularities based on observational data from the SpreadFEx campaign, Ann. Geophys., 27, 2607-2622, doi:10.5194/angeo-27-2607-2009, 2009.

Abreu, V. J., Schmitt, G. A., Hays, P. B., Meriwether Jr., J. W., Tepley, C. A., and Cogger, L. L.: Atmospheric effects on groundbased measurements of thermspheric winds, Panel. Space Sci., 31, 303-310, 1983.

Basu, S., Kudeki, E., Basu, Su., Valladares, C. E., Weber, E. J., Zengingonul, H. P., Bhattacharyya, S., Sheehan, R., Meriwether, J. W., Biondi, M. A., Kuenzler, H., and Espinoza, J.: Scintillations, plasma drifts, and neutral winds in the equatorial ionosphere after sunset, J. Geophys. Res., 101, 795-726, 1996.

Bittencourt, J. A. and Sahai, Y.: Behavior of the [OI] 6300 A emission at the magnetic equator and its relation to the vertical $\mathrm{E} \times$ B plasma drift velocity, J. Atmos. Terr. Phys., 41, 1233-1239, doi:10.1016/0021-9169(79)90026-6, 1979.

Burke, W. J., Gentile, L. C., Huang, C. Y., Valladares, C. E., and $\mathrm{Su}, \mathrm{S}$. Y.: Longitudinal variability of equatorial plasma bubbles observed by DMSP and ROCSAT-1, J. Geophys. Res., 109, A12301, doi:10.1029/2004JA010583, 2004.

Burnside, R. G., Meriwether, J. W., and Torr, M. R.: Contamination

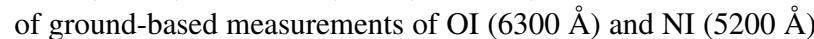
airglow by OH emissions, Planet. Space Sci., 25, 985-988, 1977.

Colerico, M. and Mendillo, M.: The current state of investigations regarding the thermospheric midnight temperature maxi- mum (MTM), J. Atmos. Sol.-Terr. Phy., 64, 1361-1369, 2002.

Colerico, M., Mendillo, M., Nottingham, D., Baumgardner, J., Meriwether, J., Mirick, J., Reinish, B., Scali, J., Fesen, C., and BIondi, M.: Coordinated measurements of F region dynamics related to the thermospheric midnight temperature maximum, J. Geophys. Res., 101, 26783-26793, 1996.

Colerico, M. J., Mendillo, M., Fesen, C. G., and Meriwether, J.: Comparative investigations of equatorial electrodynamics and low-to-mid latitude coupling of the thermosphere-ionosphere system, Ann. Geophys., 24, 503-513, doi:10.5194/angeo-24503-2006, 2006.

Drob, D. P., Emmert, J. T., Meriwether, J. W., Makela, J. J., Doornbos, E., Conde, M., Hernandez, G., Noto, J., Zawdie, 
K. A., McDonald, S. E., Huba, J. D., and Klenzing, J. H.: An update to the Horizontal Wind Model (HWM): The quiet time thermosphere, Earth and Space Science, 2, 301-319, doi:10.1002/2014EA000089, 2015.

Fisher, D. J., Makela, J. J., Meriwether, J. W., Buriti, R. A., Benkhaldoun, Z., Kaab, M., and Lagheryeb, A.: Climatologies of nighttime thermospheric winds and temperatures from Fabry-Perot interferometer measurements: From solar minimum to solar maximum, J. Geophys. Res.-Space, 120, 6679-6693, doi:10.1002/2015JA021170, 2015.

Gentile, L. C., Burke, W. J., Roddy, P. A., Retterer, J. M., and Tsunoda, R. T.: Climatology of plasma density depletions observed by DMSP in the dawn sector, J. Geophys. Res., 116, A03321, doi:10.1029/2010JA016176, 2011.

Haase, J. S., Dautermann, T., Taylor, M. J., Chapagain, N., Calais, E., and Pautet, D.: Propagation of plasma bubbles observed in Brazil from GPS and airglow data, Adv. Space Res., 47, 17581776, 2011.

Harding, B. J., Gehrels, T. W., and Makela, J. J.: A nonlinear regression method for estimating neutral wind and temperature from Fabry-Perot interferometer data, Appl. Opt., 53, 666-673, doi:10.1364/AO.53.000666, 2014.

Heelis, R. A.: Electrodynamics in the low and middle latitude ionosphere: A tutorial, J. Atmos. Sol. Terr. Phy., 66, 825-838, doi:10.1016/j.jastp.2004.01.034, 2004.

Hei, M. A., Heelis, R. A., and McClure, J. P.: Seasonal and longitudinal variation of large-scale topside equatorial plasma depletions, J. Geophys. Res., 110, A12315, doi:10.1029/2005JA011153, 2005.

Hernandez, G., Observatory, F. P., and Oceanic, N.: Contamination of the O I (P2-D2) Emission Line by the (9-3) Band of OH XII in High-Resolution Measurements of the Night Sky, 79, 1974.

Hickey, D. A., Martinis, C. R., Erickson, P. J., Goncharenko, L. P., Meriwether, J. W., Mesquita, R., Oliver, W. L., and Wright, A.: New radar observations of temporal and spatial dynamics of the midnight temperature maximum at low latitude and midlatitude, J. Geophys. Res.-Space, 119, 10499-10506, doi:10.1002/2014JA020719, 2014.

Huba, J. D. and Krall, J.: Impact of meridional winds on equatorial spread F: Revisited, Geophys. Res. Lett., 40, 1268-1272, doi:10.1002/grl.50292, 2013.

Kelley, M. C.: The Earth's ionosphere: Plasma Physics and Electrodynamics, second edition, Academic press, Elsevier, 2009.

Makela, J. J., Meriwether, J. W., Huang, Y., and Sherwood, P. J.: Simulation and analysis of a multi-order imaging Fabry-Perot interferometer for the study of thermospheric winds and temperatures. App. Optics, 50, 4403-4416, 2011.

Makela, J. J., Meriwether, J. W., Ridley, A. J., Ciocca, M., and Castellez, M. W.: Large-scale measurements of thermospheric dynamics with a multisite Fabry-Perot interferometer network: Overview of plans and results from midlatitude measurements, Int. J. Geophys., 2012, 1-10, doi:10.1155/2012/872140, 2012.

Makela, J. J., Fisher, D. J., Meriwether, J. W., Buriti, R. A., and Medeiros, A. F.: Near-continual ground-based nighttime observations of thermospheric neutral winds and temperatures over northeastern Brazil from 2009-2012, J. Atmos. Sol. Terr. Phys., 103, 94-102, doi:10.1016/j.jastp.2012.11.019, 2013.
Martinis, C., Meriwether, J., Niciejewski, R., Biondi, M., Fesen, C., and Mendillo, M.: Zonal neutral winds at equatorial and low latitudes, J. Atmos. Sol.-Terr. Phy., 63, 1559-1569, 2001.

Martinis, C., Hickey, D., Oliver, W., Aponte, N., Brum, C. G. M., Akmaev, R., Wright, A., and Miller, C.: The midnight temperature maximum from Arecibo incoherent scatter radar ion temperature measurements, J. Atmos. Sol.-Terr. Phy., 103, 129-137, doi:10.1016/j.jastp.2013.04.014, 2013.

Mendillo, M., Baumgardner, J., Colerico, M., and Nottingham, D.: Imaging science contributions to equatorial aeronomy: initial results from the MISETA program, J. Atmos. Sol.-Terr. Phy., 59, 1587-1599, 1997.

Meriwether, J., Faivre, M., Fesen, C., Sherwood, P., and Veliz, O.: New results on equatorial thermospheric winds and the midnight temperature maximum, Ann. Geophys., 26, 447-466, doi:10.5194/angeo-26-447-2008, 2008.

Meriwether, J. W., Makela, J. J., Huang, Y., Fisher, D. J., Buriti, R. A., Medeiros, A. F., and Takahashi, H.: Climatology of the nighttime equatorial thermospheric winds and temperatures over Brazil near solar minimum, J. Geophys. Res., 116, A04322, doi:10.1029/2011JA016477, 2011.

Meriwether, J. W., Makela, J. J., Fisher, D. J., Buriti, R. A., Medeiros, A., Navarro, L., Veliz, O., and Chau, J. L.: Simultaneous measurements of thermospheric winds and temperatures in the Brazilian and Peruvian longitudinal sectors, American Geophysical Union, Fall Meeting 2012.

Otsuka, Y., Kadota, T., Shiokawa, K., Ogawa, T., Kawamura, S., Fukao, S., and Zhang, S.-R.: Optical and radio measurements of a 630-nm airglow enhancement over Japan on 9 September 1999, J. Geophys. Res., 108, 1252, doi:10.1029/2002JA009594, 2003.

Pimenta, A. A., Sahai, Y., Bittencourt, J. A., and Rich, F. J.: Ionospheric plasma blobs observed by OI $630 \mathrm{~nm}$ all-sky imaging in the Brazilian tropical sector during the major geomagnetic storm of April 6-7, 2000, Geophys. Res. Lett., 34, L02820, doi:10.1029/2006GL028529, 2007.

pyglow: Upper atmosphere climatological models in Python, available at: https://github.com/timduly4/pyglow/, last access: February 2017.

Rishbeth, H.: Polarization fields produced by winds in the equatorial F region, Planet. Space Sci., 19, 357-369, doi:10.1016/00320633(71)90098-5, 1971.

Sastri, J. H. and Rao, H. N. R.: Optical interferometer measurements of thermospheric temperature at Kavalur $\left(12.5^{\circ} \mathrm{N}, 78.5^{\circ} \mathrm{E}\right)$, India, J. Atmos. Terr. Phys., 56, 775-782, doi:10.1016/00219169(94)90132-5, 1994.

Shiokawa, K., Otsuka, Y., Oyama, S., Nozawa, S., Satoh, M., Katoh, Y., Hamaguchi, Y., Yamamoto, Y., and Meriwether, J.: Development of low-cost sky-scanning Fabry-Perot interferometers for airglow and auroral studies, Earth Planets Space, 64, 10331046, doi:10.5047/eps.2012.05.004, 2012.

Spencer, N. W., Carignan, G. R., Mayr, H. G., Neimann, B. H., Theis, R. F., and Wharton, L. E.: The midnight temperature maximum in the Earth's equatorial thermosphere, Geophys. Res. Lett., 6, 444-446, 1979.

Su, S.: Low-to-Middle Latitude Ionospheric Plasma Blobs Observed by ROCSAT from 1999 to 2004, American Geophysical Union, Fall Meeting 2005.

Taori, A., Patra, A. K., and Joshi, L. M.: Gravity wave seeding of equatorial plasma bubbles: An investigation with simultaneous $\mathrm{F}$ 
region, E region, and middle atmospheric measurements, J. Geophys. Res., 116, A05310, doi:10.1029/2010JA016229, 2011.

Vila, P., Rees, D., Merrien, P., and Kone, E.: Fabry-Perot interferometer measurements of neutral winds and F2 layer variations at the magnetic equator, Ann. Geophys., 16, 731-737, doi:10.1007/s00585-998-0731-4, 1998.

Wickwar, V. B., Cogger, L. L., and Carlson, H. C.: The 6300 A O1D airglow and dissociative recombination, Planet. Space Sci., 22, 709-724, doi:10.1016/0032-0633(74)90141-X, 1974.

Wiens, R. H., Habtemichael, S., Andemariam, F., Welday, K., Criswick, J., Brown, S., and Sargoytchev, S.: Brightness variations of the northern $630 \mathrm{~nm}$ intertropical arc and the midnight pressure bulge over Eritrea, Ann. Geophys., 22, 3251-3259, doi:10.5194/angeo-22-3251-2004, 2004.
Yizengaw, E., Moldwin, M. B., Mebrahtu, A., Damtie, B., Zesta, E., Valladares, C. E., and Doherty, P. H.: Comparison of storm time equatorial ionospheric electrodynamics in the African and American sectors, J. Atmos. Sol.-Terr. Phy., 73, 156-163, 2011.

Yizengaw, E., Moldwin, M. B., Zesta, E., Biouele, C. M., Damtie, B., Mebrahtu, A., Rabiu, B., Valladares, C. F., and Stoneback, R.: The longitudinal variability of equatorial electrojet and vertical drift velocity in the African and American sectors, Ann. Geophys., 32, 231-238, doi:10.5194/angeo-32-231-2014, 2014. 